\title{
Suture Device
}

National Cancer Institute

\section{Source}

National Cancer Institute. Suture Device. NCI Thesaurus. Code C50365.

A natural (e.g., catgut, silk, or linen) or synthetic, or other (e.g., thin metal wire)

monofilament or multifilament material used surgically to close a surgical or accidental wound and to secure apposition of the edges and join tissues. 